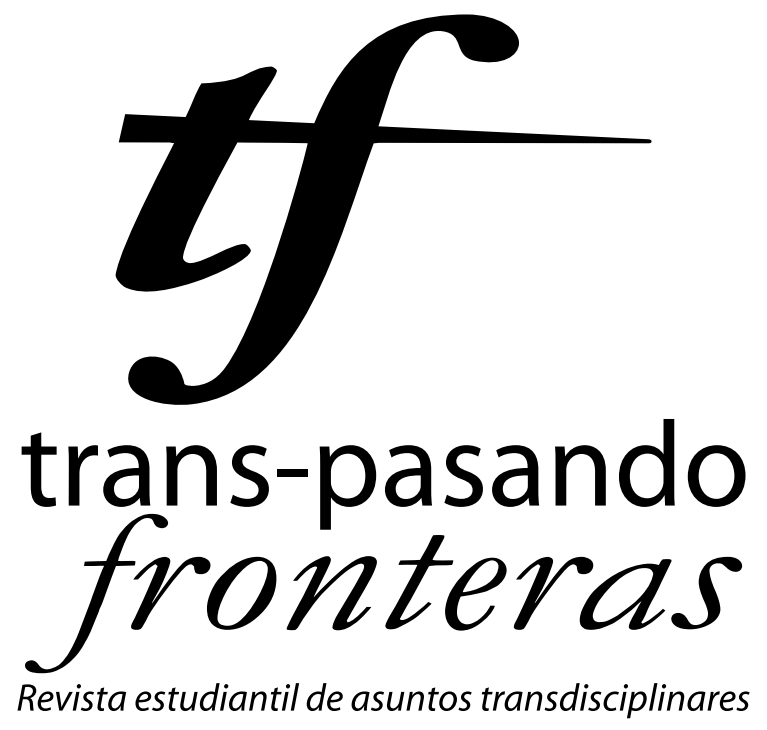

Una publicación de

Estudios

Interdisciplinarios

Jurídicos, Sociales

000 y Humanistas

ICESS

FACULTAD DE

DERECHO Y CIENCIAS

SOCIALES

然 UNIVERSIDAD 


\title{
La comunicación de hoy, ¿una aberración?
}

\author{
Hugo Andrés Arévalo González \\ (andres_3085@hotmail.com)
}

MARTÍN-BARBERO, Jesús (2005). "Poner este roto país a comunicar". En: Revista Signo y Pensamiento, Vol. XXIV, Núm. 46, Bogotá: Pontificia Universidad Javeriana. 163-169 pp.

Jesús Martín-Barbero es un filósofo español radicado en Colombia desde 1963. Tiene estudios en antropología y semiótica. De acuerdo a sus intereses investigativos en el área de comunicación, creó el Departamento de Ciencias de la Comunicación de la Universidad del Valle. Es uno de los investigadores más importantes en el ámbito comunicativo a nivel mundial.

En su texto 'Poner este roto país a comunicar', Barbero expone los fundamentos que lo llevaron a la creación de distintos espacios para repensar la comunicación. Tras sus experiencias en el ámbito académico alusivo a la materia en otros países como Perú, Venezuela, España y México, Barbero dará un giro de 180 grados a su forma de pensar una vez que se encuentre frente a frente con una situación que marcará su destino desde en su estadía en Colombia: cuenta el académico que estando en Cali, ciudad donde quiso quedarse definitivamente para dedicar su vida, estudio y trabajo, le causó curiosidad que una película permaneciera durante tres semanas en cartelera y según sus palabras, el film "constituía un récord". La película era 'La ley del monte'. Martín Barbero fue con algunos colegas a cine para ver de qué trataba la famosa película pero una vez dentro, no pudieron soportar las "carcajadas". Para Barbero y sus colegas la película no llenaba sus expectativas.

Ellos siguieron riéndose hasta que unas personas dentro de la sala de cine les dijeron que se callaran o los sacaban. Barbero se sintió perturbado porque le causaba intriga saber qué les llamaba la 
atención a esas personas de la película y que no tenía el mismo efecto con él y sus colegas. Desde ese momento su pensamiento se transformó.

La pregunta existencial del autor, giró en torno a las siguientes palabras: "Y si todo mi pomposo trabajo desalienante y 'concientizador' no le iba a servir a las personas del común, a ésas que padecían la opresión y la alienación: ¿para quién estaba trabajando? A esa experiencia la llamé pomposamente un tiempo después un 'escalofrío epistemológico". Desde aquí partirían sus investigaciones en adelante para acercar la comunicación a las necesidades de la gente.

La comunicación ha entrado en una crisis que la ha llevado a vincularse con ámbitos económicos, sociales y políticos que se alejan del bienestar de las personas. A mi parecer se destacan tres tipos de comunicación: la subyugada que es la que ejercen en su mayoría, en los medios informativos como revistas, programas de televisión, emisoras de radio reconocidas - $\mathrm{e}$ influenciadas por poderes económicos o políticos- y con poco contenido que permita cultivar beneficiosamente a las personas; la comunicación de laboratorio, que es la que permanece en urgencias continuamente desde las academias en las que se les analiza y se replantean teorías de acuerdo a las prácticas, dinámicas y movimientos sociales, y que busca en general, la reflexión y unión de comunicación y comunidad. Y por último, la comunicación camaleónica, esta ha sido la que se ha dado cuenta por un lado, de la crisis comunicativa que se padece hoy en día por la falta de propuestas, que termina convirtiéndose en comunicación subyugada, y por otro lado, ha notado las dificultades económicas que existen desde la comunicación de laboratorio para ejercer la disciplina con el objetivo de vincular comunidades y denuncia de problemas sociales y buscar -en lo posible- sus soluciones convocando y haciendo un llamado tanto a las instituciones estatales y gobierno, como a las mismas academias y ciudadanos.

Esta comunicación es camaleónica porque se ha visto obligada a mutar, a desviar su cauce; es la que ha encontrado "oportunidad" en la crisis, y por esto su acercamiento con el mundo económico empresarial mediante las campañas de responsabilidad social, han permitido "evidenciar", "denunciar" y "visibilizar" malestares sociales que deben partir desde el derecho mismo de las instituciones, y que necesitan ser atendidos con urgencia. Ahora el término "in- 
dustrias culturales" que es muy diciente, da para entender a la cultura como una industria, exotizar y volver un circo a las personas o colectivos con diversos talentos o habilidades, con la aparente pretensión de apoyarlos o impulsarlos. En resumen, lo abordan Theodor Adorno y Max Horkheimer en La Industria Cultural: el arte sólo es una fuente de gratificación para ser consumida.

Todos entendemos que el mundo está inmerso en un modelo económico neoliberal y lo que menos importa es ayudar al prójimo si eso implica perder tiempo y sobre todo, dinero. Es una verdad innegable, y viene de la mano con su modalidad: lo que no se adapta, se transforma, o desaparece, y parece que la comunicación que yo llamo “camaleónica" lo entendió hace rato. Tal cual lo ve el filósofo español Fernández Liria cuando expresa que ' 'los medios de comunicación, es decir, las condiciones materiales del uso público de la palabra, están secuestradas por poderes privados descomunales. No es extraño que el ciudadano sienta que no tiene nada que hacer en política, excepto, votar cada cuatro años". En pocas palabras y más poético, lo comenta el periodista y escritor uruguayo Eduardo Galeano: ' nos mean y los diarios dicen que llueve',
Este tipo de comunicación es una aberración sí y no: sí, porque rompe con la filosofía de la comunicación de comunicar de manera desinteresada las necesidades sociales con las instituciones estatales, ciudadanía, academia y gobierno; no, porque de manera estratégica conecta de manera recursiva nodos de interés entre empresacolectivo-particular, y ambos se benefician -si bien se expone una imagen circense del sujeto apoyado, y el que apoya obtiene descuentos tributarios, posiciona marca y mejora credibilidad.

El discurso del capitalismo y la comunicación que le sigue el juego, es de insatisfacción: para suplir la falta de goce, es necesario que se consuma más y más, por lo que hay que reflexionar hasta qué punto queremos llegar, sabiendo que tenemos mayores posibilidades económicas y sociales si seguimos como vamos, a costa de nuestra humanidad, de nuestra historia. En palabras de Barbero, sería: "se hace más nítida la demanda de un comunicador no intermediario de los intereses mercantiles, sino mediador de las demandas sociales y las formas comunitarias de comunicación". 